\title{
Functional Relations between General Economic Indicators, Premium Income and Claims Costs in Different Insurance Sectors *
}

\author{
by Fritz Becker **
}

\section{Introduction}

The economic analysis of the relationship between general economic indicators and indicators of the development of whole classes of the insurance business is still in its infancy. Some recent publications (e.g. Helten [3] [4], Sigma [11]), using comparative time-series diagrams, have tried to illustrate some intuitively expected correlations. These studies can however be regarded only as an incentive for further research, based on less naive statistical methods such as : trend projection, exponential smoothing, spectral analysis, regression analysis, Box-Jenkins approach (see GDV [2]).

De Wit [10] has proposed to proceed in four stages :

(i) production of standardized definitions for the indicators of insurance business;

(ii) collection of statistical data ;

(iii) specification and quantification of the functional relations;

(iv) implementation of a global model in a computer system.

His approach has been followed in the present paper. Section 2 provides some comments on stages (i) and (ii), as they relate to the German situation. Section 3 presents the results of a regression analysis, based on German data and pertaining to the relationship between premium income and claims costs in whole insurance branches on the one hand, and general economic indicators on the other hand. Stage (iv) has not been envisaged here.

To my knowledge, the results presented in section 3 are the first based on this kind of approach for Germany. Therefore, they should be confirmed or invalidated by further research on this subject.

\section{Methodological problems}

\subsection{Problems with the data}

Currently, difficulties for empirical analysis arise from the lack of sufficiently long, well-defined indicators of various classes of insurance business.

* Revised version of a paper presented at a seminar on "Insurance cycles" organized by the "Geneva Association" in March 1979.

** University of Mannheim, Institute of Insurance Science. 
It would be desirable to have long time-series of earned premiums and of the costs of all claims for loss and damage, which happened in this period.

In fact, the German Insurance Association (GDV) publishes :

- gross premiums ;

- insurance payments ;

- gross loss ratios.

Moreover, there are some interruptions in these time-series since 1960.

The German Insurance Authority (BAV) separates data into :

(i) the sums from the balance sheets of all supervised insurance companies, of : booked premiums, expenditures for payment of losses and damages (settled and outstanding), of the business year and of the preceding years ;

(ii) the gross results of the so-called "large insurance companies" (which have more than a million premium income and which have together about $99 \%$ of the private insurance market) on : booked and earned premiums with supplementary payments, expenditures for claims of losses and damages during the business year (sum of payments and reserves for pending claims) and the loss ratio.

Also since 1975, BAV publishes data on expenses for insurance business and the expense ratio. The differences between these data series are easily recognized in fig. 1 and more so in fig. 2 , which shows growth rates of premium income from private accident insurance. ${ }^{1}$

It is obvious that these different time series will give us different results in an economic analysis; especially in the period 1973 to 1977 when there are great discrepancies.

There are two other problems with the data. First, the published time series are results taken from balance sheets and, therefore, are influenced by changes introduced by the supervisory authority in the rules governing balance sheets.

Secondly, it is a basic decision as to whether one will analyse real or nominal data. To illustrate this problem, the percentage increase in nominal earned premium from industrial fire insurance is compared in fig. 3 with three time-series deflated by different price indices. Because there are great deviations, it is enough for our illustration to work with nominal time series only.

The form of the data should depend on the aims of the analysis. There are five types of data transformations:

1. $X_{t}$ the absolute levels of time series $X_{t}$

2. $X_{t}-X_{t-1}=\Delta X_{t}$

the absolute first order differences

3. $\ln X_{t}$

the logarithmic levels

1 See tables 1 and 2 for a list of abbreviations used throughout this paper. 
4. $100\left(X_{t}-X_{t-1}\right) / X_{t-1}$

the yearly rate of increase of $X_{t}$, the so-called "growth rate"

5. $100\left(\ln X_{t}-\ln X_{t-1}\right)=\Delta \ln X_{t}$

the first differences of the logarithms of the levels of the time series. They are approximately the same as the growth rate, except that positive and negative deviations are weighted equivalently.

Because most economic time series have strong trends, it is often necessary to work with relative increases to avoid autocorrelation and multicollinearity.

\subsection{The method of regression analysis}

The insurance time series being too short, spectral analysis [6] [7] and the BoxJenkins-approach [1] [8] are not feasible.

Regression analysis [5] [9] allows us to quantify the expected causal relationship between insurance and macroeconomic indicators.

The dynamic multiple regression model with lagged endogenous variable $y_{t-\tau}$ can be written :

$$
y_{t}=\hat{b}_{o}+\hat{b}_{1} y_{t-1}+\ldots+\hat{b}_{z} y_{t-\tau}+\hat{b}_{\tau+1} x_{\tau+1}+\ldots+\hat{b}_{n} x_{n t}+u_{t}
$$

with $y_{t}=$ endogenous variable

$x_{i t}=$ exogenous variable, $i=\tau+1, \ldots, n$

$\hat{b}_{j}=$ estimates of the regression coefficients $b_{j}, j=0, \ldots, n$

$u_{t}=$ stochastic residuals

$K=$ number of exogenous factors ( $n$ or $n+1$, if there is a constant)

The lagged variables $y_{t-\tau}$ and the exogenous variables $x_{i t}$ together are predetermined variables.

In some relations the Cochrane-Orcutt autoregressive transformation is necessary, because the disturbances are first order autocorrelated, i.e.

$$
y_{t}=\hat{b}_{o}+\hat{b}_{1} x_{1 t}+\hat{b}_{2} x_{2 t}+\varepsilon_{t}
$$

with $\varepsilon_{t}=\hat{\varrho}^{\bullet} \varepsilon_{t-1}+u_{t} \quad \hat{\varrho}<1$

The used computer programm TSP calculates some statistical tests to help in discriminating between several regression equations for one endogenous variable :

(i) $t$-values of the estimated parameters $b_{j}$ which should be somewhat greater than two in the normal case if we are to reject the null hypothesis that $b_{j}=0$;

(ii) $\bar{R}^{2}$, the coefficient of determination which is equal to the squares multiple correlation coefficient adjusted for degrees of freedom. In the case of trended time series the $\bar{R}^{2}$-values have hardly any power in discriminating between various estimated equations. But in the case of stationary time series (relative rates of increase) $\bar{R}^{2}$-values greater than .40 or .50 are considered high;

(iii) the Durbin-Watson statistics is used to test for the presence of first order autocorrelated disturbances. The null hypothesis of no autocorrelation is rejected if DW differs significantly from two. Usually the DW-test is tabled for $\tau$ greater than 12 or 15 and for $K$ up to 6 . 


\section{Estimated equations by the method of Ordinary-Least-Square (OLS)}

\subsection{Analysed time series and data used}

The data on the " earned gross premium of the direct business with supplementary payments" and the "gross expenses for claims of the business year" published by the German Insurance Authority were analysed for the following classes of insurance :

KH $\quad(1962-1977)$ third party automobile insurance

K (1962 - 1977) total automobile insurance

FI $\quad(1960-1974)$ industrial fire insurance

FBU (1960 - 1974) business interruption insurance

F $\quad(1960-1973)$ total fire insurance

\subsection{Regression analysis of the time series of the automobile insurance}

The iterative search for good regression equations will be explained using the example of third party automobile insurance.

In the first step the time series and their differences of logarithms are graphed.

In fig. 4 it is obvious that the time series are trended. It seems clear, from the growth rates in fig. 5, that there is a delay of one period between the increase in the costs of damages and the premiums, as can be seen from the maxima and minima.

The second step consists of the search for exogenous variables, which could have a causal influences on the endogenous variable. These are listed in table 2 with some lagged endogenous variables. Alternative equations explaining the expenses of the third party automobile insurance are shown in tables 3 and 4 .

Table 5 shows the "best" equations with values of the statistical tests. The nominal costs of damages of third party automobile insurance (5.1) are a linear function of a constant, of GNP and of the quantity of new licensed motorcars.

The $t$-values of the coefficients, which are noted below in brackets, indicate precise parameter estimates, the $\bar{R}^{2}$-values $(0.993)$ could hardly be better and the Durbin-Watson statistics (1.925) indicate no first order autocorrelation.

In fig. 6 the real and the estimated nominal time series from (5.1) are plotted. Figure 7 shows the time series of fig. 6 as first differences of the logarithms, and allows a comparison of the forecasting quality of equation (5.1) with that of equations (5.2) and (5.3).

Two of the estimated equations for the differences of logarithms of expenses of motor liability insurance have $\bar{R}^{2}$-values about 0.60 (eq. 5.2 and eq. 5.3). These equations were transformed by the Cochrane-Orcutt method because there was autocorrelation in the residuals. The $t$-values and DW-statistics imply a good fit. The graphs in fig. 8 and fig. 9 show the results of forecasts using (5.2) and (5.3). These equations are obviously better than the equation expressed in levels; see (5.1) and fig. 7.

The regressions for earned premium income of automobile liability insurance $(\mathrm{PVKH})$ are shown in table 6 and pictured in fig. 10 and 11. 
Although an autoregressive data transformation was performed in (6.1), the $t$-value of the constant and, especially, the DW-coefficient show the incomplete specification of the relation, whereas in (6.2) the statistical tests are satisfactory $\left(\bar{R}^{2}=0.978\right.$; DW $1.636 ; t=8.8$ and 25.8 ).

In the case of first differences of logarithms, the great eruption in 1971 could be accounted for by a dummy variable as in (6.4) or a moving-average from 1969 to 1971 (6.5). Figure 10 pictures the result for $\Delta \ln$ PVKH without any data transformation (6.3). Equation (6.4) is pictured in figure 11.

As was to be expected, the results for PVK and LK hardly differ from those for the third party automobile insurance. Equations (6.1) and (7.1) have similar statistical tests. In (7.3) S71 accounts for the eruption of 1971. The regressions (7.4) and (7.5) look like (5.1) and 5.2).

\section{3: Regression analysis of the time series of the fire insurance}

Before analysing the various time series on fire insurance the original data are transformed by first order moving average to remove irregularities and possible mistakes in the definition of the periods. The consequence of this transformation for the costs of damages of the industrial fire insurance is shown in fig. 12.

The estimated equations for fire insurance are shown in tables 8,9 and 10. Forecasts given by some of these equations are plotted in fig. 13 to 17.

No equation with satisfactory statistical tests could be estimated for the first differences of the logarithms of the costs of damages of the loss of profits fire insurance. The "best" one (10.4) has $t$-values of 0.6 and 1.7 and a coefficient of determination $\bar{R}^{2}$ of only 0.1198 .

The structure and the right-hand variables of the estimated "best" equations for the premiums (PVF, PVFI and PVFBU) are always the same: the levels $(8.1,9.1$ and 10.1) are influenced by a constant, the lagged premium income and the private building investments. In the case of the rates of increase (8.2, 9.2 and 10.2) the same functions were used without the constant term. For illustration the actual and the fitted time series are graphed in fig. 13, 15 and 17.

Whereas the premium income from fire insurance depends on building investments, with the exception of $\Delta \ln$ LF the regression analysis of the costs of damages gives better results for the exogenous variable investments in machinery and equipment $(8.3,9.3,9.4,10.3$ and with restriction 10.4). Also there are changes in the structure of the functions.

\section{Summary and concluding remarks}

This study is a first attempt to forecast the indicators "premium income" and " costs of damages" of the German non-life insurance industry based upon their dependence on macro-economic indicators.

The absolute values and the rates of increase of the indicators of the automobile and fire insurance have been estimated using the method of Ordinary-Least-Squares (OLS). The results indicate a high correlation between the insurance business and the economy. 
We are thus able to say that, if the problems coming from the data of the insurance time series could be solved, the method of regression analysis would allow us to approach our future aim of implementing a global computer system for long range forecasting of the expected evolution of the whole non-life insurance branch.

\section{REFERENCES}

1. BOX, G.E.P. \& G. M. JENKINS : Time Series Analysis - Forecasting and Control, San Francisco, 1976.

2. GDV - Gesamtverband der Deutschen Versicherungswirtschaft (Ed.): Der Einfluss der Konjunktur auf versicherungswirtschaftliche Grössen - empirische Analyse, unpublished report of the Department of Economics and Statistics, Cologne, 1978.

3. HELTEN, E.: "Business cycles and insurance", The Geneva Papers on Risk and Insurance, No. 6, October 1977, 59-75.

4. HELTEN, E.: "Die Bedeutung der Konjunkturforschung für die Versicherungswirtschaft ", Versicherungswirtschaft, 33 (1978), 12-19.

5. JOHNSTON, J. : Econometric Methods, New York, 1963.

6. KOENIG, H., \& J. WOLTERS : Einführung in die Spektralanalyse ökonomischer Zeitreihen, Meisenheim am Glan, 1972.

7. LEINER, B.: Spektralanalyse - Einführung in Theorie und Praxis moderner Zeitreihenanalyse, Opladen, 1976.

8. NELSON, C. R. : Applied Time Series Analysis - For Managerial Forecasting, San Francisco, 1973.

9. SCHNEEWEISS, H. : Ökonometrie, Würzburg and Vienna, 1974.

10. WIT, G. W. de : "Konjunkturschwankungen in der Versicherungswirtschaft", unpublished manuscript, Rotterdam, 1978.

11. ... "Die Konjunkturempfindlichkeit der Versicherung", Sigma, No. 6 (1978).

\section{Table 1:}

List of abbreviations used for the insurance business

GDV : German Insurance Association

BAV : German Insurance Authority

P : Gross premium income

PG : Booked premiums

PV : Earned premiums

KH : Third-party automobile insurance

K : Total automobile insurance

FI : Industrial fire insurance

FBU : Business interruption insurance

F : Total fire insurance

L : Claims for losses 
Table 2:

List of exogenous and some lagged endogenous variables

KFZB rolling stock of motorcars

KFZN new registrated motorcars

AUSLG production load

PROD productivity

RW, RA, RF some rates of interest/yields of bonds, shares and fixed interest stocks price indices of :

$\mathrm{PHH} \quad$ cost of living of all private households

PCP private consumption

PYBSP GNP

PIANL buildings, machinery and equipment

PIAUS machinery and equipment

\begin{tabular}{ll} 
YBSP & GNP \\
CP & private consumption \\
CST & consumption of government \\
IM & import \\
EX & export \\
YV & disposable private income \\
SH, SHO, SHN & sundry definitions of savings \\
\multicolumn{2}{c}{ sundry investment definitions }
\end{tabular}

IAUSB machinery and equipment, gross

IBAUB buildings, gross

IVOR changing in the stock investment

IAUSP machinery and equipment, private

IBAUP buildings, private

IBAUW private-enterprise housebuildings

IANLB buildings, machinery and equipment, gross

IGESB total investments, gross

M1 quantity of money

GUNV undistributed profits

QSPAR savings rate

BEV whole population

EWP working population

AL unemployed

ALQ unemployment rate

lagged endogenous variables (e.g. third party automobile insurance)

$\begin{array}{ll}\text { KHSH }_{-\tau} & \text { loss frequency } \\ \text { KHSD }_{-\tau} & \text { average loss } \\ \text { KHSB }_{-\tau} & \text { burning cost } \\ \text { PVKH }_{-\tau} & \text { earned premium } \\ \text { LKH }_{-\tau} & \text { cost of damages }\end{array}$




\section{Table 3 :}

Some of the estimated regression equations for the absolute cost of damages in the third party automobile insurance (LKH)

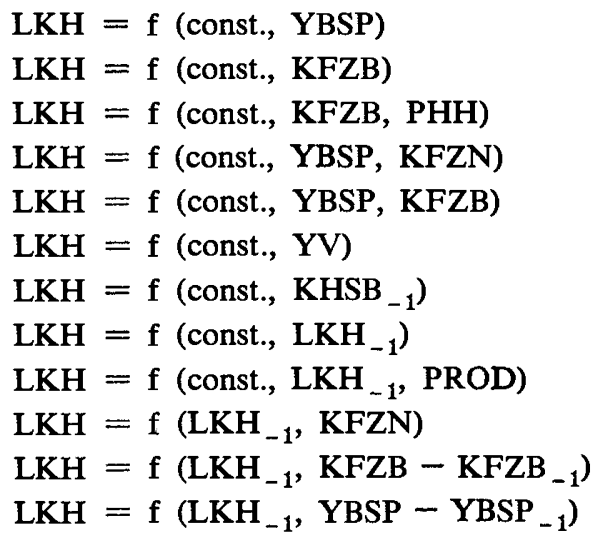

Table 4:

Some of the estimated regression equations for the first differences in the logarithms of the cost of damages in the third party automobile insurance ( $\Delta \ln L K H$ )

$\Delta \ln$ LKH $=\mathrm{f}$ (const., $\Delta \ln$ YBSP)

$\Delta \ln \mathrm{LKH}=\mathrm{f}$ (const., $\Delta \ln$ PROD)

$\Delta \ln \mathrm{LKH}=\mathrm{f}(\Delta \ln \mathrm{KFZB})$

$\Delta \ln \mathrm{LKH}=\mathrm{f}\left(\Delta \ln \mathrm{KFZB}, \Delta_{-1} \ln \mathrm{LKH}\right)$

$\Delta \ln \mathrm{LKH}=\mathrm{f}(\Delta \ln \mathrm{KFZB}, \Delta \ln \mathrm{PHH})$

$\Delta \ln \mathrm{LKH}=\mathrm{f}(\Delta \ln \mathrm{KFZB}, \Delta \ln \mathrm{YV})$

$\Delta \ln \mathrm{LKH}=\mathrm{f}(\Delta \ln \mathrm{KFZB}, \Delta \ln \mathrm{YBSP})$

$\Delta \ln \mathrm{LKH}=\mathrm{f}\left(\Delta_{-1} \ln \mathrm{LKH}, \Delta \ln \mathrm{KFZN}\right)$

$\Delta \ln \mathrm{LKH}=\mathrm{f}\left(\Delta_{-1} \ln \mathrm{LKH}\right)$

$\Delta \ln \mathrm{LKH}=\mathrm{f}\left(\Delta_{-1} \ln \mathrm{LKH}, \Delta \ln \mathrm{PROD}\right)$

Table 5:

Estimated "best" equations for LKH and $\Delta \ln$ LKH with statistical tests.

$$
\begin{aligned}
& \text { LKH }=-2.2561+0.007399 \mathrm{YBSP}+0.0007994 \mathrm{KFZN}+u_{t} \\
& \begin{array}{ccc}
(t=8.8) & (t=21.9) & (t=3.5) \\
\overline{\mathbf{R}}^{2}=0.994 & \mathrm{DW}=1.971
\end{array}
\end{aligned}
$$

(5.2) $\Delta \ln \mathrm{LKH}=-0.7307 \Delta_{-1} \ln \mathrm{LKH}+3.860 \Delta \ln \mathrm{KFZB}+0.7611 \varepsilon_{t-1}+u_{t}$

$$
\overline{\mathbf{R}}^{2}=0.800 \quad \text { (9.2) } \mathrm{DW}=2.455
$$

(5.3) $\Delta \ln \mathrm{LKH}=0.7758 \Delta_{-1} \ln \mathrm{LKH}+0.4550 \Delta \ln \mathrm{KFZN}-0.9333 \varepsilon_{t-1}+u_{t}$

$$
\begin{array}{ll}
(15.4) & \text { (7.2) } \\
\bar{R}^{2}=0.617 & \mathrm{DW}=2.210
\end{array}
$$


Table 6:

Estimated "best" equations for PVKH and $\triangle \ln P V K H$ with statistical tests

(6.1) $\mathrm{PVKH}=\underset{(1.8)}{1.8205}+\underset{(6.6)}{0.9355 \mathrm{LKH}_{-1}}+\underset{(4.9)}{0.8038} \varepsilon_{t-1}+u_{t}$

$$
\overline{\mathrm{R}}^{2}=0.982 \quad \mathrm{DW}=0.972
$$

(6.2) $\mathrm{PVKH}=-3.021+0.3737 \mathrm{KHSB}_{-1}$

$$
\overline{\mathrm{R}}^{2}=0.981 \quad \mathrm{(25.8)} \quad \mathrm{DW}=1.588
$$

(6.3) $\Delta \ln \mathrm{PVKH}=-2.0578+0.9974 \Delta_{-1} \ln \mathrm{LKH}$

$$
\overline{\mathrm{R}}^{2}=0.644 \quad \mathrm{DW}=1.703
$$

(6.4) Dummy variables S71 $(1971=1 ; 0)$

$$
\begin{aligned}
& \Delta \ln \mathrm{PVKH}=0.889 \Delta_{-1} \ln \mathrm{PVKH}+0.6976 \Delta \ln \mathrm{KFZB}+20.470 \mathrm{S71} \\
& \text { (4.2) (4.7) } \\
& \overline{\mathrm{R}}^{2}=0.688 \quad \mathrm{DW}=1.300
\end{aligned}
$$

(6.5) Moving average from 1969 to 1971 in the absolute values of PVKH $\Delta \ln$ PVKH $=0.4341 \Delta_{-1} \ln$ PVKH $+1.5387 \Delta \ln$ KFZB $+0.7360 \varepsilon_{t-1}+u_{t}$

$$
\begin{aligned}
& \text { (2.5) } \\
& \overline{\mathrm{R}}^{2}=0.7723 \\
& \mathrm{DW}=1.858
\end{aligned}
$$

\section{Table 7:}

Estimated "best" equations for the total motor insurance $(P V K, \Delta \ln P V K, L K, \Delta \ln L K)$ with statistical tests

(7.1) PVK $=2.3802+1.0004 \mathrm{LK}_{-1}+0.8297 \varepsilon_{t-1}+u_{t}$

$$
\begin{aligned}
& \text { (2.1) } \\
& \overline{\mathbf{R}}^{2}=0.990 \\
& \mathrm{DW}=0.992
\end{aligned}
$$

(7.2) $\Delta \ln$ PVK $=-0.8400+0.9283 \Delta_{-1} \ln \mathrm{LK}+u_{t}$

$$
\overline{\mathbf{R}}^{2}=0.706 \quad \mathrm{DW}=1.757
$$

(7.3) $\Delta \ln \mathrm{PVK}=0.3959 \Delta_{-1} \ln \mathrm{PVK}+0.7184 \Delta \ln \mathrm{KFZB}+18.03 \mathrm{~S} 71+u_{t}$

$$
\begin{array}{cc}
(4.4) & (5.0) \\
\overline{\mathbf{R}}^{2}=0.869 & \mathrm{DW}=1.449
\end{array}
$$

(7.4) LK

$$
\begin{aligned}
& =-2.8725+0.0009772 \mathrm{KFZN}+0.009165 \mathrm{YBSP}+u_{t} \\
& \text { (8.4) } \\
& \overline{\mathbf{R}}^{2}=0.993 \\
& \mathrm{DW}=1.674
\end{aligned}
$$

(7.5) $\Delta \ln \mathrm{LK}=-0.6532 \Delta_{-1} \ln \mathrm{LK}+3.7201 \Delta \ln \mathrm{KFZB}+0.7656 \varepsilon_{t-1}+u_{t}$

$$
\overline{\mathbf{R}}^{2}=0.742
$$

$$
\mathrm{DW}=2.353
$$


Table 8 :

Estimated "best" equations for the total fire insurance $(F)$
(8.1) $\mathrm{PVF}=-0.5032+0.7355 \mathrm{PVF}_{-1}+0.01664 \mathrm{IBAUP}_{-1}+u_{t}$

$$
\begin{array}{ccc}
(7.3) & (5.2) & (4.7) \\
\overline{\mathbf{R}}^{2}=0.993 & \mathrm{DW}=1.187
\end{array}
$$
(8.2) $\Delta \ln \mathrm{PVF}=0.7674 \Delta_{-1} \ln \mathrm{PVF}+0.4483 \Delta_{-1} \ln \mathrm{IBAUP}+u_{t}$
(6.2)
$\overline{\mathrm{R}}^{2}=0.786$

$$
\mathrm{DW}=2.426
$$
(8.3) LF

$$
\begin{aligned}
& =-0.2194+0.6389 \mathrm{LF}_{-1}+0.01309 \mathrm{IAUSP}+u_{t} \\
& \text { (2.9) } \\
& \widetilde{\mathbf{R}}^{2}=0.984
\end{aligned}
$$

(8.4) $\Delta \ln \mathrm{LF}=7.304+0.7090 \Delta_{-1}$ IBAUP $\overline{\mathbf{R}}^{2}=0.462$

$$
\mathrm{DW}=1.698
$$

Table 9 :

Estimated " best" equations for the industrial fire insurance (FI)

$$
\begin{aligned}
& \text { (9.1) PVFI }=-0.3333+0.5852 \text { PVFI }_{-1}+0.0101 \text { IBAUP }_{-1}+u_{t} \\
& \text { (6.3) (5.1) } \quad \text { (6.1) } \\
& \overline{\mathbf{R}}^{2}=0.992 \\
& \mathrm{DW}=1.669 \\
& \text { (4.6) } \\
& \overline{\mathrm{R}}^{2}=0.680 \\
& \mathrm{DW}=1.814
\end{aligned}
$$

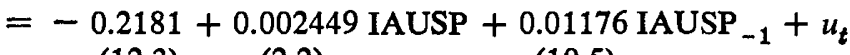

$$
\begin{aligned}
& \text { (12.3) } \\
& \overline{\mathbf{R}}^{2}=0.994 \\
& \mathrm{DW}=1.565 \\
& \overline{\mathrm{R}}^{2}=0.691 \\
& \mathrm{DW}=1.875
\end{aligned}
$$



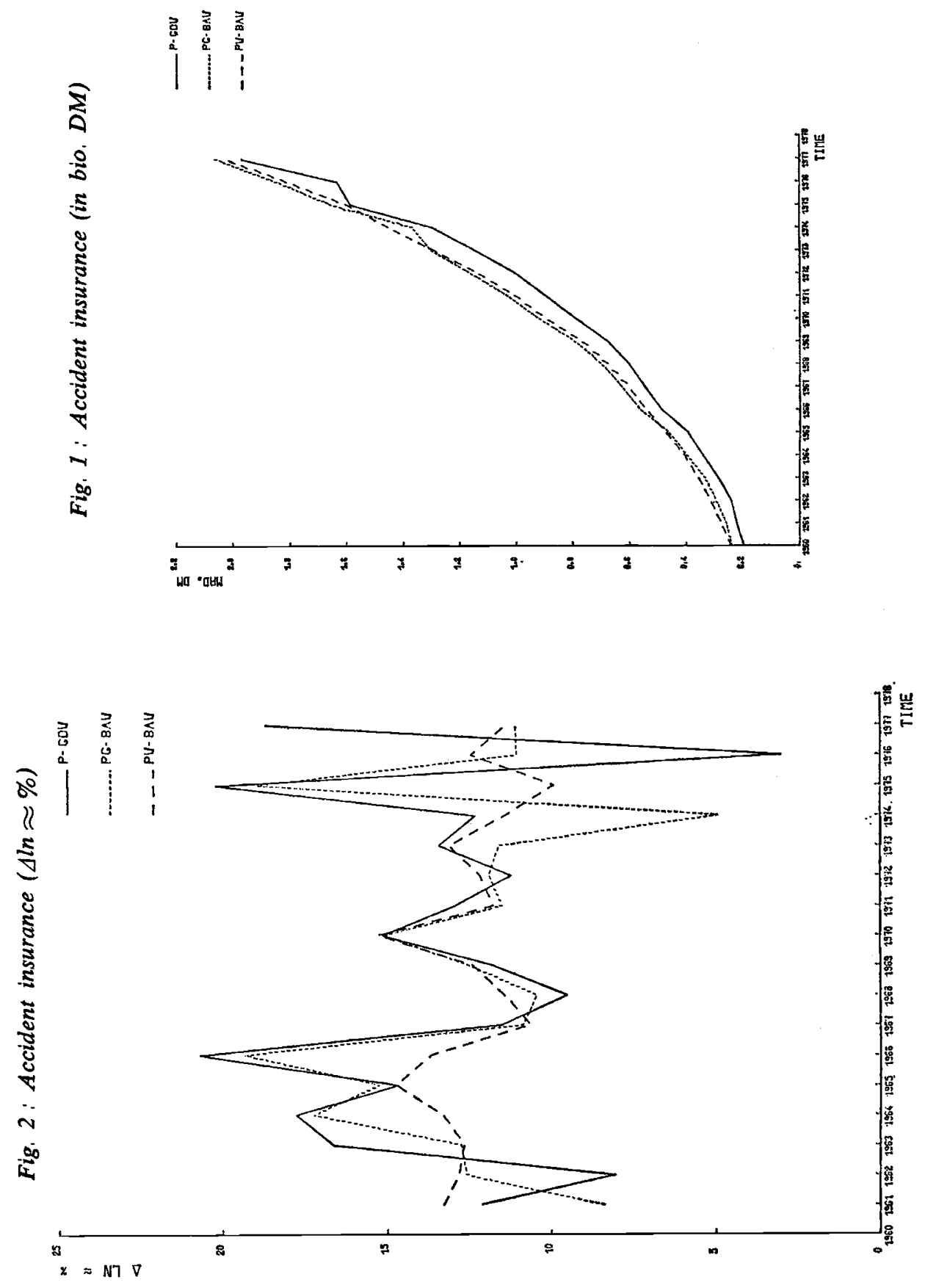

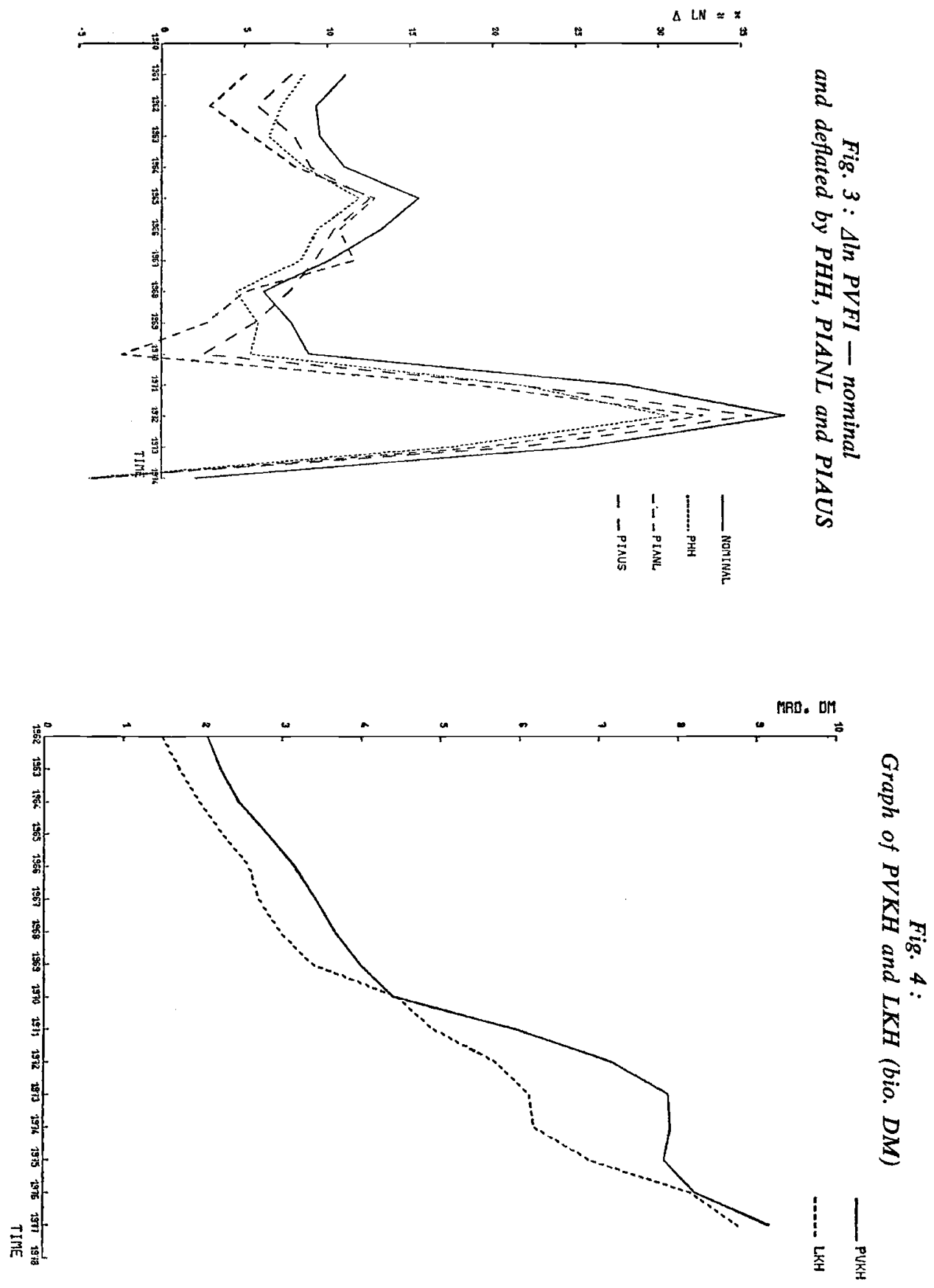

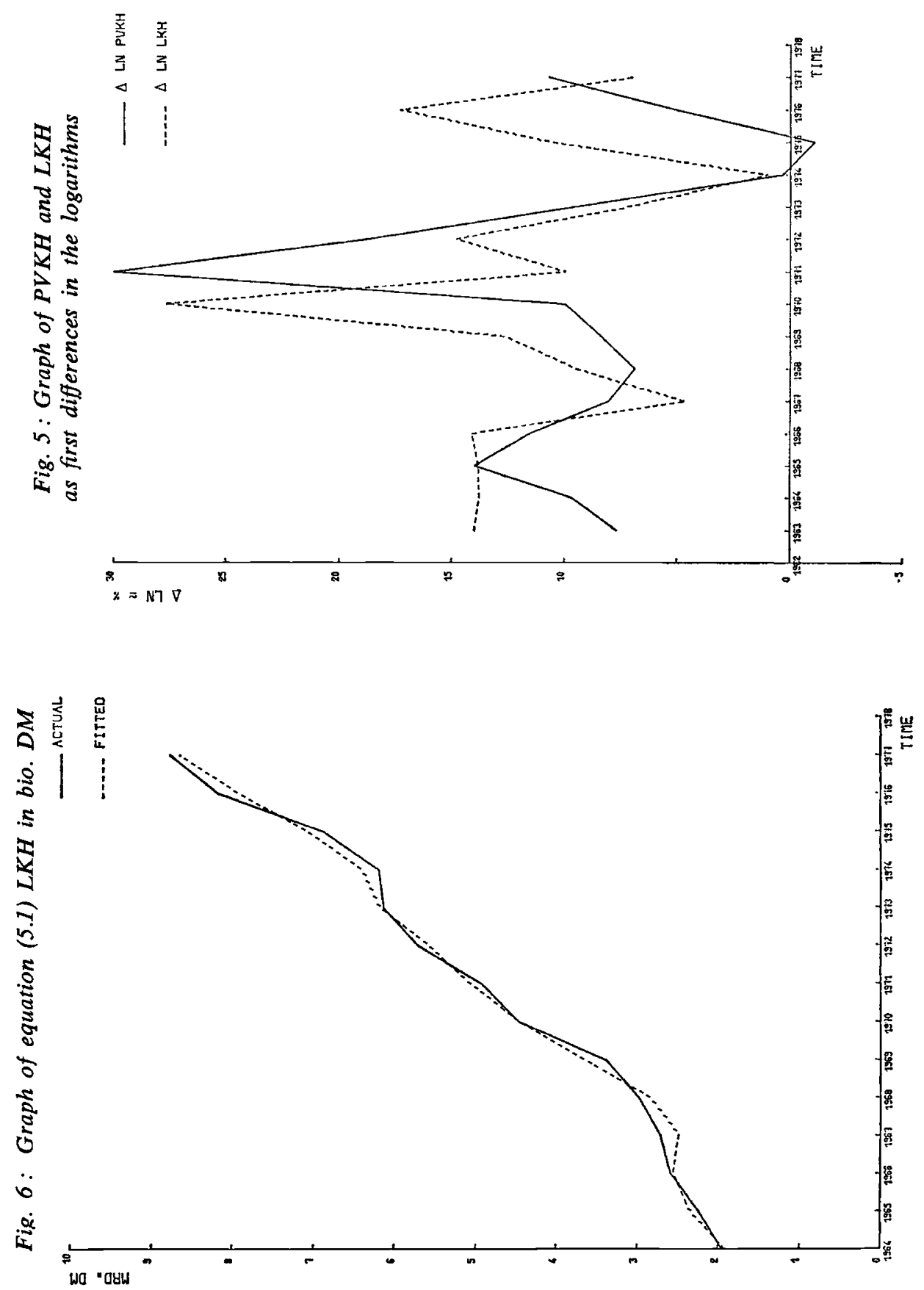

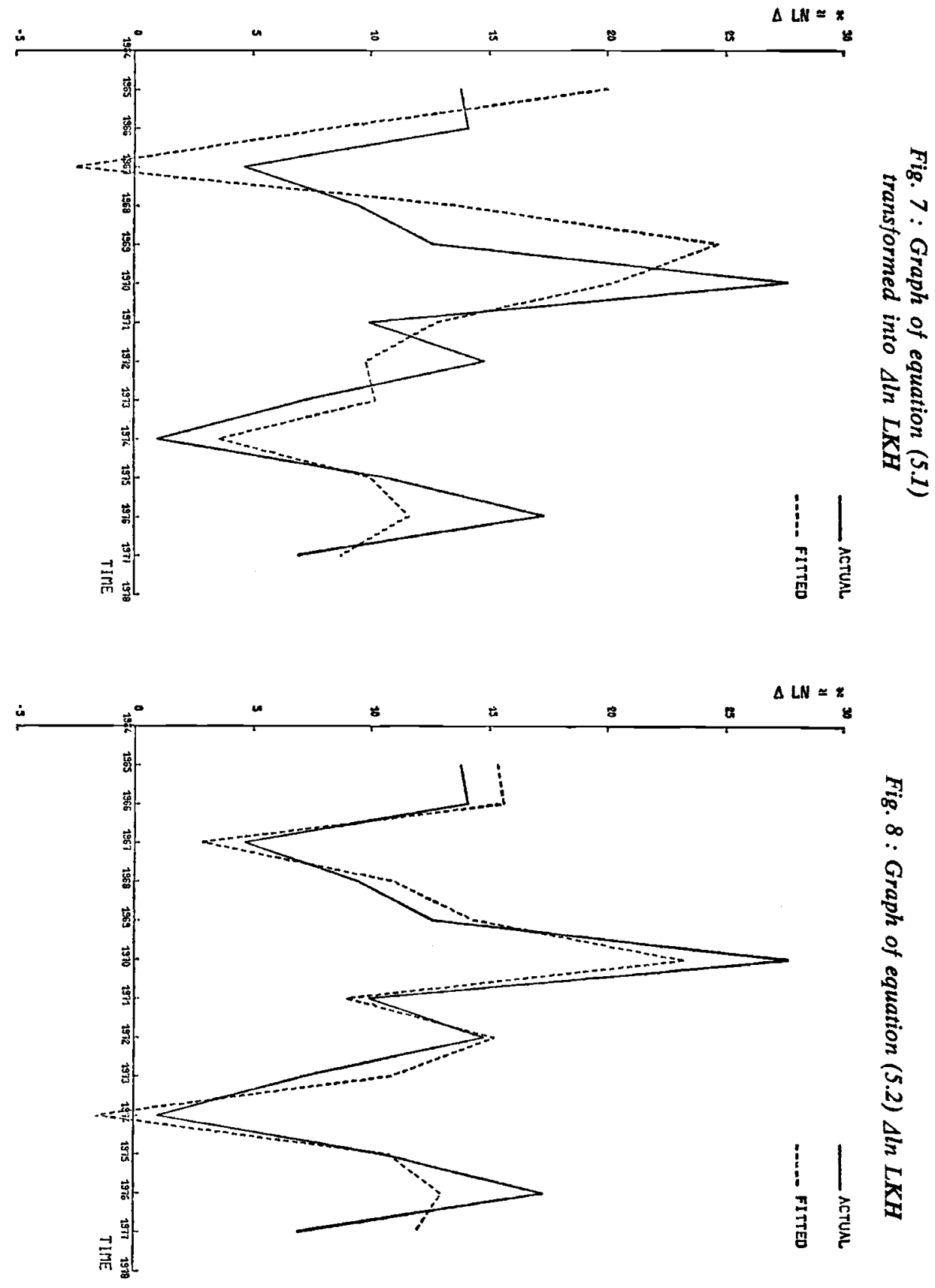

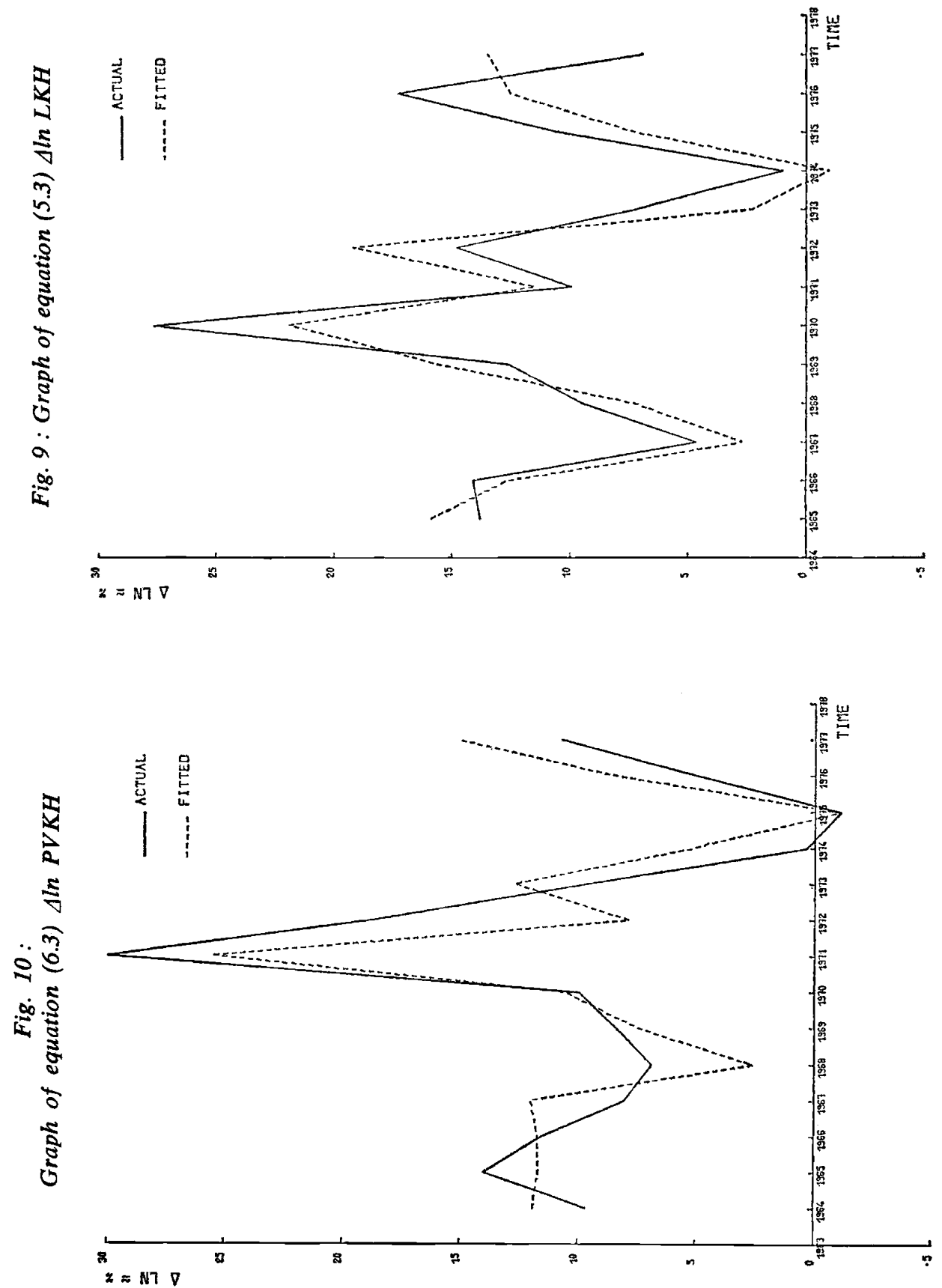

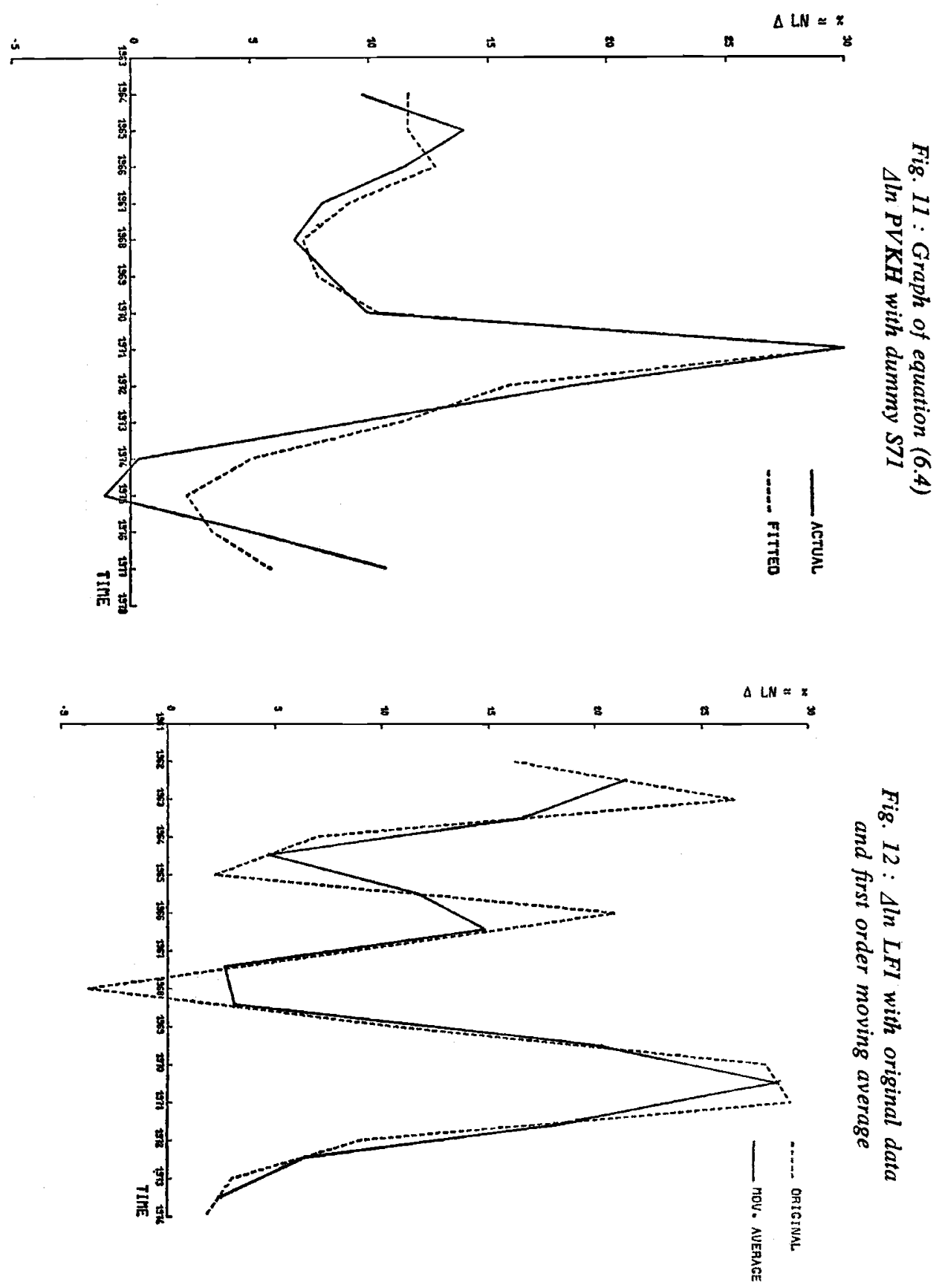

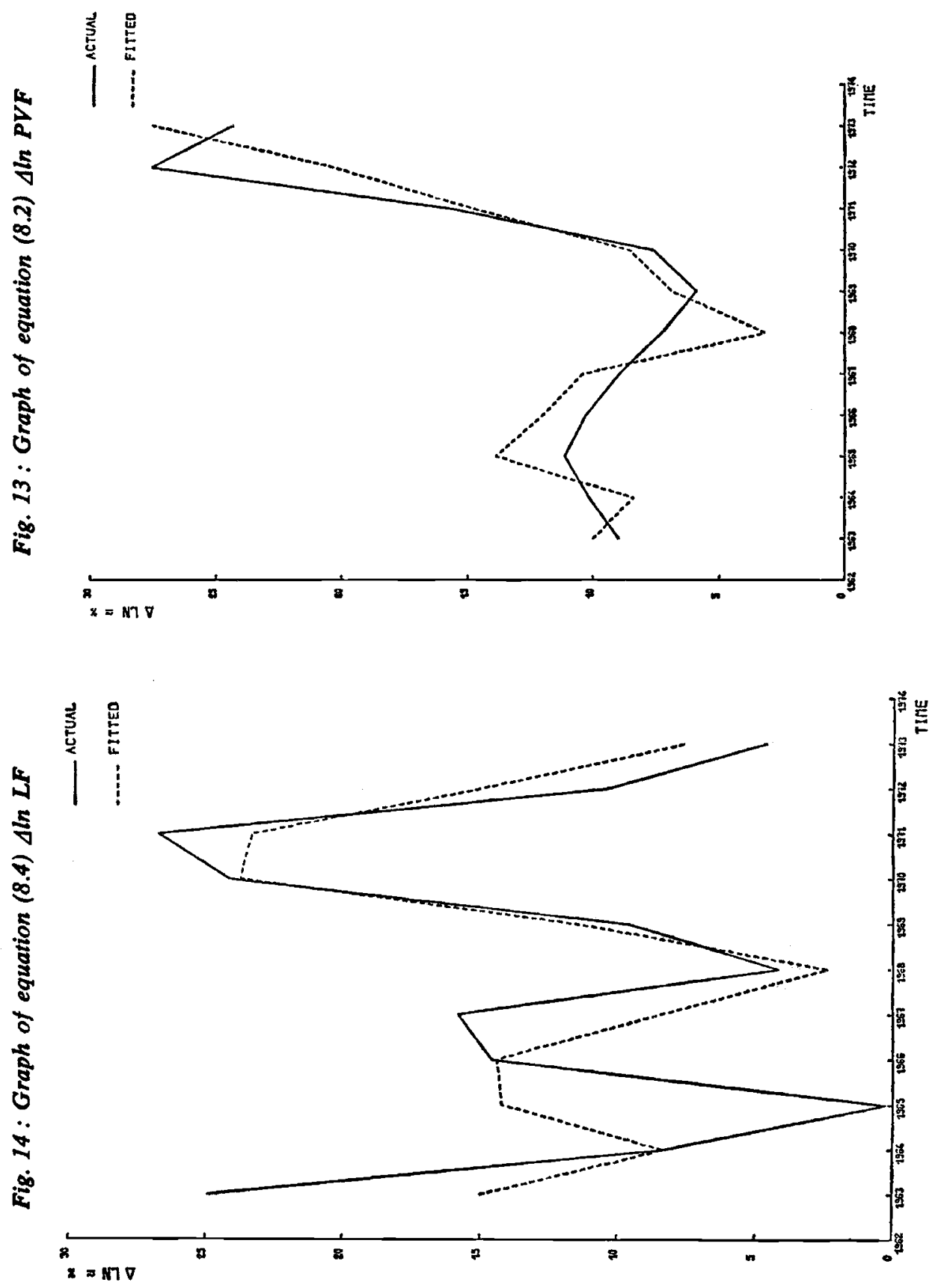

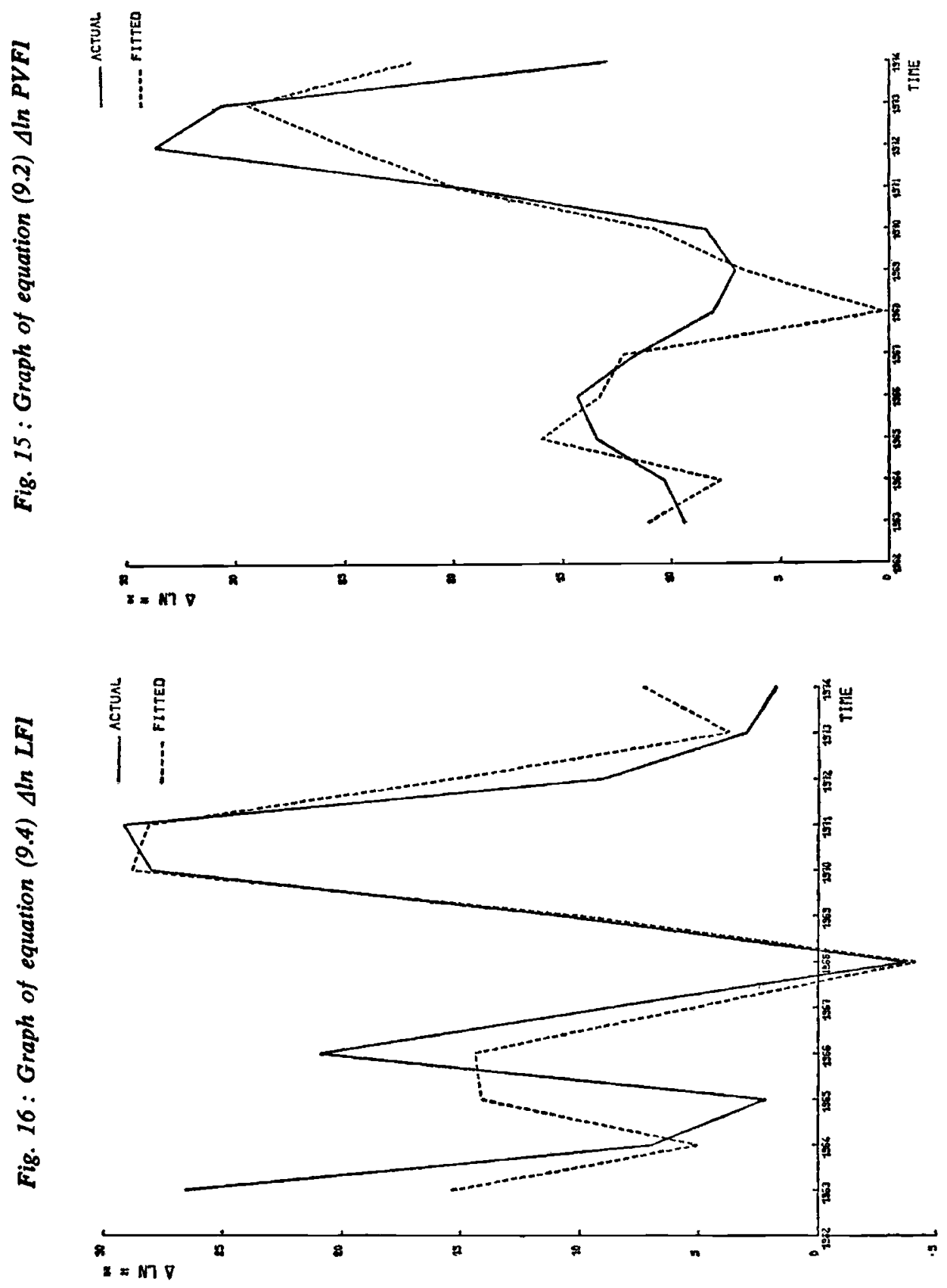

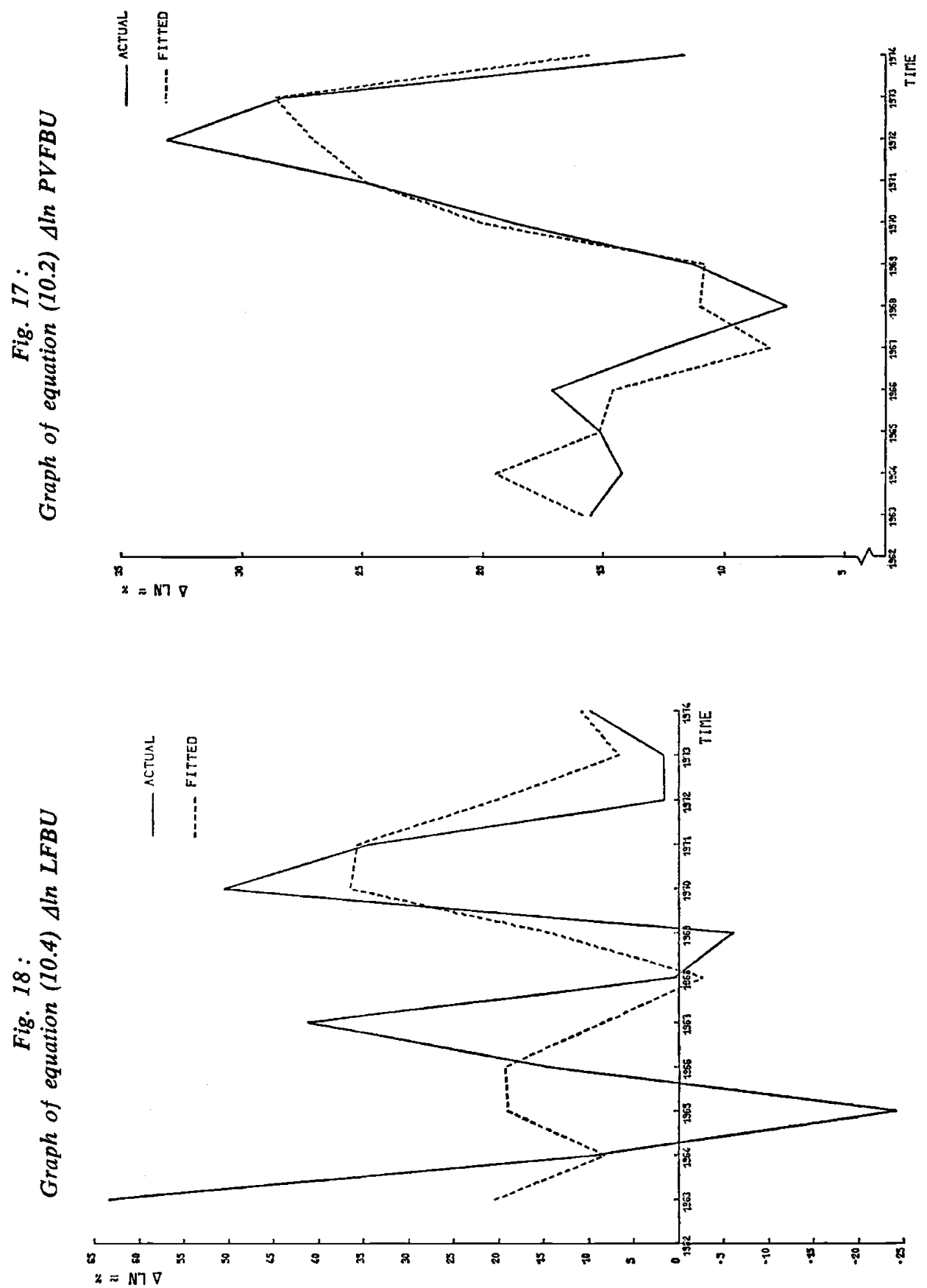

62 